\title{
Irreversible ocean thermal expansion under carbon dioxide removal
}

\author{
Dana Ehlert ${ }^{1, a}$ and Kirsten Zickfeld $^{1}$ \\ ${ }^{1}$ Department of Geography, Simon Fraser University, 8888 University Drive, V5A 1S6 Burnaby, B.C., Canada \\ anow at: GEOMAR Helmholtz Centre for Ocean Research Kiel, \\ Biogeochemical Modelling, Düsternbrooker Weg 20, 24105 Kiel, Germany
}

Correspondence: Dana Ehlert (dehlert@geomar.de)

Received: 10 May 2017 - Discussion started: 24 May 2017

Revised: 15 November 2017 - Accepted: 21 November 2017 - Published: 5 March 2018

\begin{abstract}
In the Paris Agreement in 2015 countries agreed on holding global mean surface air warming to "well below $2{ }^{\circ} \mathrm{C}$ above pre-industrial" levels, but the emission reduction pledges under that agreement are not ambitious enough to meet this target. Therefore, the question arises of whether restoring global warming to this target after exceeding it by artificially removing $\mathrm{CO}_{2}$ from the atmosphere is possible. One important aspect is the reversibility of ocean heat uptake and associated sea level rise, which have very long (centennial to millennial) response timescales. In this study the response of sea level rise due to thermal expansion to a $1 \%$ yearly increase of atmospheric $\mathrm{CO}_{2}$ up to a quadrupling of the pre-industrial concentration followed by a $1 \%$ yearly decline back to the pre-industrial $\mathrm{CO}_{2}$ concentration is examined using the University of Victoria Earth System Climate Model (UVic ESCM). We find that global mean thermosteric sea level (GMTSL) continues to rise for several decades after atmospheric $\mathrm{CO}_{2}$ starts to decline and does not return to pre-industrial levels for over 1000 years after atmospheric $\mathrm{CO}_{2}$ is restored to the pre-industrial concentration. This finding is independent of the strength of vertical sub-grid-scale ocean mixing implemented in the model. Furthermore, GMTSL rises faster than it declines in response to a symmetric rise and decline in atmospheric $\mathrm{CO}_{2}$ concentration partly because the deep ocean continues to warm for centuries after atmospheric $\mathrm{CO}_{2}$ returns to the pre-industrial concentration. Both GMTSL rise and decline rates increase with increasing vertical ocean mixing. Exceptions from this behaviour arise if the overturning circulations in the North Atlantic and Southern Ocean intensify beyond pre-industrial levels in model versions with lower vertical mixing, which leads to rapid cooling of the deep ocean.
\end{abstract}

\section{Introduction}

Policy makers agreed to "holding the increase in the global average temperature to well below $2{ }^{\circ} \mathrm{C}$ above pre-industrial levels and pursuing efforts to limit the temperature increase to $1.5^{\circ} \mathrm{C}$ above pre-industrial levels" under the Paris Agreement in 2015 (Paris Agreement, 2015). The national pledges ("nationally determined contributions") under this agreement, however, are not sufficient to meet this target (Peters et al., 2015; Rogelj et al., 2016a). At the same time, global mean surface air temperature would remain elevated even if all $\mathrm{CO}_{2}$ emissions were to cease (Matthews and Caldeira, 2008; Gillett et al., 2011; Matthews and Zickfeld, 2012; Zickfeld et al., 2013), implying that the mere cessation of emissions would not enable recovery of a warming target for centuries to millennia after exceeding it. Therefore, it has been discussed to artificially remove $\mathrm{CO}_{2}$ from the atmosphere using a number of techniques such as reforestation or direct air capture (Fuss et al., 2016). It should be noted that none of these techniques has yet been tested on a large scale (Fuss et al., 2016; Smith et al., 2016). However, most future scenarios that do not exceed the $2{ }^{\circ} \mathrm{C}$ warming target include carbon dioxide removal (CDR) and show a peak and decline in atmospheric $\mathrm{CO}_{2}$ stronger than would be achieved by only zeroing emissions (Smith et al., 2016). For example, the only representative concentration pathway not exceeding $2{ }^{\circ} \mathrm{C}$, RCP 2.6, includes CDR (Meinshausen et al., 2011). 
The decline in radiative forcing induced by CDR raises the question of the reversibility of anthropogenic climate change, i.e. to what extent it is possible to revert to either a preindustrial climate or another warming target such as $2^{\circ} \mathrm{C}$ and the related climate state by artificially removing $\mathrm{CO}_{2}$ from the atmosphere.

Previous studies have shown that global mean surface air warming is reversible on human timescales but lags the $\mathrm{CO}_{2}$ decline due to the ocean's thermal inertia (Boucher et al., 2012; Tokarska and Zickfeld, 2015; Zickfeld et al., 2016). Other aspects, such as precipitation or sea ice, are also reversible but lag the temperature response (Boucher et al., 2012). (Wu et al., 2010) show a hysteresis behaviour of the hydrological cycle under declining temperatures also due to the ocean's thermal inertia. The effectiveness of CDR to lower atmospheric $\mathrm{CO}_{2}$ is impeded as $\mathrm{CO}_{2}$ outgasses from natural carbon sinks in response to CDR. This outgassing increases with increasing amounts of CDR, and thus CDR becomes less effective the higher the amounts of CDR (Tokarska and Zickfeld, 2015). Furthermore, the total amount of CDR needed for reverting to the initial $\mathrm{CO}_{2}$ concentration is higher than total positive $\mathrm{CO}_{2}$ emissions (MacDougall et al., 2015; Zickfeld et al., 2016). This means that more carbon needs to be artificially removed from the atmosphere than was initially emitted due to the lag of surface air temperature relative to the atmospheric $\mathrm{CO}_{2}$ concentration. This effect is even stronger if the permafrost carbon feedback, which accounts for additional carbon emissions from thawing permafrost, is included (MacDougall et al., 2015). Another important finding of the reversibility research under $\mathrm{CDR}$ is that the ratio between temperature change and cumulative emissions (the transient climate response to cumulative carbon emissions, TCRE) differs between atmospheric $\mathrm{CO}_{2}$ increase and decline phases. This difference would need to be taken into account when estimating total allowable emissions for a certain warming target after overshoot (Zickfeld et al., 2016).

Previous studies found thermosteric sea level rise to be in principle reversible (Bouttes et al., 2013; Zickfeld et al., 2013; MacDougall, 2013), but reversing it on centennial timescales requires large amounts of CDR, which are likely infeasible with currently discussed technologies (Tokarska and Zickfeld, 2015). (Bouttes et al., 2013) show by using a two-layer model of the atmosphere-ocean system (Gregory, 2000; Geoffroy et al., 2013) that the decline in thermosteric sea level in response to zeroed or negative radiative forcing (with preceding positive radiative forcing) is due to a strong temperature decline in the upper layer (atmosphere and ocean surface layer) relative to the lower layer (deep ocean), which enables the release of heat. This decline in thermosteric sea level cannot be explained with a zero-dimensional energy balance model (0-D EBM) where the ocean is modelled as an infinite heat sink, which cannot spontaneously release heat. Limitations of the two-layer model are that it has only two different heat capacities and it does not include the ocean overturning circulation. Both shortcomings lead to too slow heat release under CDR relative to an atmosphere-ocean general circulation model (AOGCM; Bouttes et al., 2013).

(Zickfeld et al., 2017) investigate the mechanisms of thermosteric sea level rise and decline induced by emissions of short-lived radiative forcing agents, such as methane, and the cessation of those emissions. Positive emission rates followed by a cessation of emissions of short-lived radiative forcing agents induces an increase and decline in radiative forcing, which is similar to the change in radiative forcing that can be induced by positive $\mathrm{CO}_{2}$ emissions and CDR as the concentration of short-lived forcing agents declines relatively fast in the atmosphere after cessation of their emissions. (Zickfeld et al., 2017) show that the rate of sea level change from thermal expansion can be approximated with the difference between radiative forcing and a term representing radiative damping to space, which corresponds to a 0-D EBM. This model shows that a negative difference between radiative forcing and global mean surface air temperature (GMSAT) change scaled by the climate feedback parameter enables declining global mean ocean temperatures and thus declining thermosteric sea level. Note that in contrast to (Bouttes et al., 2013), Zickfeld et al. (2017) do not assume ocean heat uptake in the 0-D EBM to be proportional to temperature change, which is justified for increasing but not decreasing radiative forcing.

In this study we further explore the physical mechanisms that determine the reversibility of thermosteric sea level rise. In particular, we examine the sensitivity of the reversibility of thermal expansion to parameterization of sub-grid-scale ocean mixing. This is important because parameterization of sub-grid-scale ocean mixing strongly affects the timescale of ocean heat uptake and release, and the processes that determine ocean mixing are still incompletely accounted for in most climate models. We examine the reversibility of thermal expansion and the processes involved in the context of symmetrically increasing and decreasing atmospheric $\mathrm{CO}_{2}$ concentration.

The model used for this study is a model of intermediate complexity, which allows for simulations on long (millennial) timescales. Section 2 describes this model and the simulations performed. The results of these simulations are presented in Section 3. In Sect. 4 the conclusions from those results are drawn and discussed.

\section{Model and simulations}

\subsection{Model}

Simulations for this study were performed using the University of Victoria Earth System Climate Model version 2.9 (UVic ESCM 2.9; Eby et al., 2009), a model of intermediate complexity. The physical model consists of an atmosphere energy balance model, a general circulation ocean model, a sea ice model, and a land surface scheme. All components 
include coupled carbon cycle descriptions and have a resolution of $1.8^{\circ}$ (meridional) $\times 3.6^{\circ}$ (zonal). This version of UVic ESCM does not include an ice sheet model, and we only discuss the sea level rise due to thermal expansion of the ocean in the following sections.

The atmosphere model is a vertically integrated energymoisture balance model, which includes planetary long wave, and water vapour feedbacks. Clouds are represented in the albedo of the atmosphere but cloud feedbacks are not included. A wind field is prescribed, but a dynamic wind feedback is included as changes in that wind field due to changes in surface air temperature are considered. The land is represented using a simplified version of the Met Office Surface Exchange Scheme (MOSES; Meissner et al., 2003; Cox et al., 1999), coupled to the dynamic vegetation model TRIFFID (Top-down Representation of Interactive Foliage and Flora Including Dynamics; Cox, 2001).

The ocean is described with a three-dimensional general circulation model with 19 vertical layers. It is the Geophysical Fluid Dynamic Laboratory (GFDL) Modular Ocean Model (MOM; Weaver et al., 2001), which is coupled to a thermodynamic sea ice model, an inorganic carbon cycle model, a marine biology model (Schmittner et al., 2005), and a sediment model (Eby et al., 2009). Sub-grid-scale ocean mixing is described via momentum diffusivity (or viscosity) and tracer diffusivity (Weaver et al., 2001). The following discussion focuses on parametrization of tracer diffusivity and the term ocean mixing only refers to the diffusion of tracers. This diffusion of tracers is parameterized as diffusion along isopycnals (surfaces of constant density) and diffusion across isopycnals. The diffusivity along isopycnals is set to $800 \mathrm{~m}^{2} \mathrm{~s}^{-1}$ and an additional parametrization is implemented to account for instabilities where isopycnals are tilted (Gent and McWilliams, 1990). This additional parameter, referred to as Gent and McWilliams thickness diffusivity, is also set to $800 \mathrm{~m}^{2} \mathrm{~s}^{-1}$. Mixing across isopycnals (diapycnal mixing) is described via a vertical mixing scheme as there is no practical difference between vertical and diapycnal mixing due to isopycnal slope limitations in the ocean model. There are three vertical mixing scheme options in the UVic ESCM 2.9: a vertically and laterally constant mixing scheme, a depth-dependent but laterally constant (Bryan and Lewis; Bryan and Lewis, 1979) mixing scheme, and a tidal mixing scheme, where mixing due to the dissipation of tidal energy over topography is added to a constant background diffusion parameter (Schmittner et al., 2005).

\subsection{Simulations}

Different model versions of UVic ESCM are developed by using different vertical ocean mixing schemes and diffusivities (Table 1). The range of diffusivities is chosen to achieve the widest possible range in ocean heat uptake while keeping the model stable and not necessarily to closely reproduce observed ocean tracer distributions. However, for the tidal mix- ing scheme the range of background diffusivities is informed by studies that aimed at finding a range that best fits tracer observations (Schmittner et al., 2009; Goes et al., 2010; Ross et al., 2012). Mixing along isopycnals only entails small variations in ocean heat uptake (Ehlert et al., 2017) and is therefore set to the default value in all model versions.

The default model setting is a Bryan and Lewis vertical mixing scheme with a diffusivity of $0.3 \mathrm{~cm}^{2} \mathrm{~s}^{-1}$ in the thermocline and $1.3 \mathrm{~cm}^{2} \mathrm{~s}^{-1}$ in the deep ocean. In a set of sensitivity experiments this range is shifted to higher values of $0.5-1.5 \mathrm{~cm}^{2} \mathrm{~s}^{-1}\left(k_{\mathrm{v}, \mathrm{B} \& \mathrm{~L}}\right.$ high $)$ and lower values of $0.1-1.1 \mathrm{~cm}^{2} \mathrm{~s}^{-1}\left(k_{\mathrm{v}}, \mathrm{B} \& \mathrm{~L}\right.$ low), while the vertical profile within these ranges remains the same. The mixing scheme is changed from Bryan and Lewis to a vertically constant mixing scheme $\left(k_{\mathrm{v}, \text { const }}\right)$, where the diffusivity is set to a value between 0.05 and $1.0 \mathrm{~cm}^{2} \mathrm{~s}^{-1}$. Additionally, a tidal mixing scheme is used $\left(k_{\mathrm{v}, \text { tidal }}\right)$ and the background diffusivity is set to a value between 0.1 and $0.45 \mathrm{~cm}^{2} \mathrm{~s}^{-1}$.

Each model version is spun up for 6000 years under preindustrial (year 1800) boundary conditions. All model versions are close to equilibrium with the year 1800 forcing and model drift in ocean temperature is small (Supplement, Fig. S1) by the end of the spin-up simulations. Note that the model does not require flux adjustment. Subsequently, all model versions are forced with an idealized scenario of a $1 \%$ yearly increase in atmospheric $\mathrm{CO}_{2}$ concentration until quadrupling of the pre-industrial concentration (simulation year 140 ) followed by a $1 \%$ yearly decrease until preindustrial levels are restored (simulation year 280). The simulations are continued with constant pre-industrial $\mathrm{CO}_{2}$ concentration for another 1120 simulation years. The global mean ocean temperature change in the forced simulations is 1 order of magnitude larger than the global mean ocean temperature drift in the last 1000 spin-up years, which does not exceed $0.045^{\circ} \mathrm{C}$. An in-depth discussion of the drift and implications for the results presented in Sect. 3 is included in the Supplement.

The transient climate response (TCR), which is the GMSAT change at a doubling of atmospheric $\mathrm{CO}_{2}$ relative to preindustrial, ranges from 1.58 to $2.24^{\circ} \mathrm{C}$ between the different model versions (Table 1). This range lies within the EMIC TCR range of 0.8 to $2.5^{\circ} \mathrm{C}$ (Eby et al., 2013). The equilibrium climate sensitivity (ECS), which is the equilibrium temperature change at doubling of the pre-industrial $\mathrm{CO}_{2}$ concentration, for the default model version is $3.5^{\circ} \mathrm{C}$ (Eby et al., 2013). For comparison, the likely ranges for the TCR and ECS in the Intergovernmental Panel for Climate Change (IPCC) Fifth Assessment Report (AR5) are 1 to $2.5^{\circ} \mathrm{C}$ and 1.5 to $4.5^{\circ} \mathrm{C}$ respectively (Collins et al., 2013). A discussion of the ocean heat uptake efficiency between the model versions and comparison to other models can be found in (Ehlert et al., 2017). 
Table 1. Description of different model versions and their names as referred to in the text and figures. $k_{\mathrm{V}}$ is the vertical diffusivity. The pre-industrial state of the different model versions is shown for global mean surface air temperature (SAT) and the maximum of the Atlantic meridional overturning stream function (AMOC). The transient climate response (TCR) is calculated as GMSAT change averaged over a decade centred around year 70 .

\begin{tabular}{llcccc}
\hline Experiment & Vertical mixing scheme & $k_{\mathrm{v}}\left(\mathrm{cm}^{2} \mathrm{~s}^{-1}\right)$ & SAT $\left({ }^{\circ} \mathrm{C}\right)$ & AMOC $(\mathrm{Sv})$ & TCR $\left({ }^{\circ} \mathrm{C}\right)$ \\
\hline default & Bryan and Lewis & $0.3-1.3$ & 13.39 & 21.6 & 1.87 \\
$k_{\mathrm{v}, \text { B\&L low }}$ & Bryan and Lewis & $0.1-1.1$ & 13.16 & 12.7 & 2.04 \\
$k_{\mathrm{v}, \mathrm{B} \& \mathrm{~L}}$ high & Bryan and Lewis & $0.5-1.5$ & 13.52 & 25.8 & 1.67 \\
$k_{\mathrm{v}, \text { const }} 0.05$ & vertically constant & 0.05 & 12.89 & 9.8 & 2.24 \\
$k_{\mathrm{v}, \text { const }} 0.3$ & vertically constant & 0.3 & 13.33 & 21.4 & 1.91 \\
$k_{\mathrm{v}, \text { const }} 1.0$ & vertically constant & 1.0 & 16.67 & 32.3 & 1.58 \\
$k_{\mathrm{v}, \text { tidal }} 0.1$ & tidal & 0.1 & 13.15 & 14.4 & 2.00 \\
$k_{\mathrm{v}, \text { tidal }} 0.2$ & tidal & 0.2 & 13.32 & 19.3 & 1.87 \\
$k_{\mathrm{v}, \text { tidal }} 0.45$ & tidal & 0.45 & 13.49 & 25.8 & 1.70 \\
\hline
\end{tabular}

\section{Results}

\subsection{Reversibility of sea level rise}

In this section we focus on the thermosteric sea level rise and decline for the default ocean mixing setting (black curves in all figures with line plots), and Sect. 3.2 discusses the effect of different ocean mixing settings on this response. Global mean surface air temperature (GMSAT) declines shortly after the decline in $\mathrm{CO}_{2}$ is prescribed (Fig. 1a). Global mean thermosteric sea level (GMTSL) continues to rise for another 80 years until it starts declining (Fig. 1b). The decline is much slower than the rise in GMTSL despite a symmetrically increasing and decreasing atmospheric $\mathrm{CO}_{2}$ concentration. To further investigate the mechanism of the GMTSL rise and decline we investigate ocean temperature as a proxy for GMTSL as the depth profile of ocean temperature gives insight into the distribution of heat in the ocean and will enable comparison with a two-layer ocean model in Sect. 3.2. The choice of ocean temperature as a proxy for thermosteric sea level rise is reasonable as changes in global mean ocean temperature (GMOT) and changes in GMTSL are nearly linearly related and follow a similar temporal evolution (Fig. 1b and $\mathrm{c}$ ).

The decline in GMOT and thus GMTSL is very slow because the warming signal from the previous increase in $\mathrm{CO}_{2}$ still penetrates into the deep ocean centuries after the radiative forcing returns to zero (year 280) and heat that entered the mid-ocean is mixed into the surface layer very slowly (Fig. 2a). Thus, despite cooling of the surface layer, the deep ocean is still heating, except at high latitudes where the deep ocean cools (Fig. 3b). This cooling is likely associated with an intensification of meridional overturning circulation in the North Atlantic and the Southern Ocean respectively, which overshoots the original value after $\mathrm{CO}_{2}$ concentration returns to pre-industrial levels (Fig. 6; see also discussion in Sect. 3.2). The decline in GMOT lags the decline in atmospheric $\mathrm{CO}_{2}$ concentration and also the decline in global mean surface air temperature (GMSAT) to such an extent that by the end of the simulation (1120 years after $\mathrm{CO}_{2}$ concentration is restored to pre-industrial levels) GMOT and thus thermosteric sea level have not returned to pre-industrial levels. As seen in previous studies (Boucher et al., 2012), GMOT exhibits hysteresis relative to change in radiative forcing as GMOT remains elevated despite zero radiative forcing (Fig. 1d). This hysteresis behaviour is due to a lagged response of GMOT to $\mathrm{CO}_{2}$, rather than to a change in the state of the ocean.

In previous studies it has been assumed that GMTSL change is proportional to GMSAT changes on multicentennial timescales and thus to radiative forcing (Rahmstorf, 2007; Bouttes et al., 2013). However, this assumption does not hold for declining radiative forcing (Bouttes et al., 2013); (Zickfeld et al., 2017) therefore suggested the following relationship, which holds also under declining radiative forcing:

$\frac{\mathrm{d} \eta}{\mathrm{d} t}=\alpha \mathrm{RF}-\beta \Delta T$,

where $\eta$ is the sea level rise due to thermal expansion, RF is the radiative forcing, and $\Delta T$ is the temperature change relative to a reference year. $\beta / \alpha$ corresponds to the climate feedback parameter $\lambda$ in $\mathrm{Wm}^{-2} \mathrm{~K}^{-1}$ by analogy of the above equation with the zero-dimensional energy balance equation (i.e. $\mathrm{d} \eta / \mathrm{d} t \propto$ ocean heat uptake $=\mathrm{RF}-\lambda \Delta T$ ). Applying this framework to the simulation results discussed here shows that while GMTSL rises, the radiative forcing is larger than $\lambda \Delta T$ (Fig. 4). However, when $\lambda \Delta T$ is larger than the radiative forcing, induced by the lag of the GMSAT decline relative to the decline in radiative forcing, GMTSL declines. Thus the decline of GMOT and GMTSL is due to a negative radiation imbalance at the top of the atmosphere. 
(a)

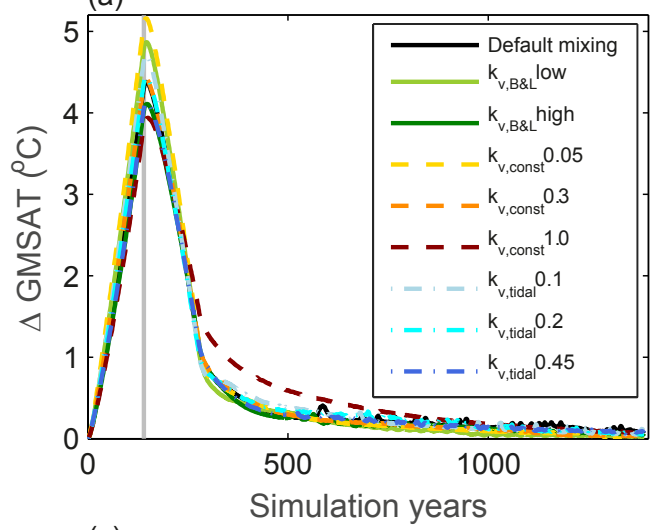

(c)

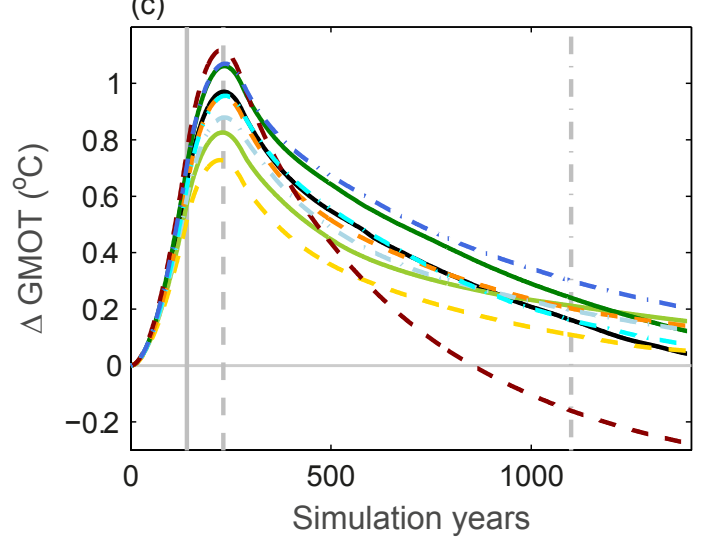

(b)

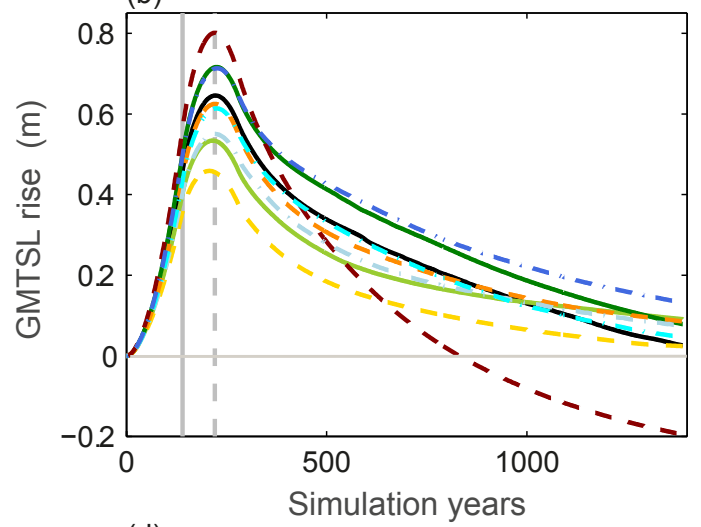

(d)

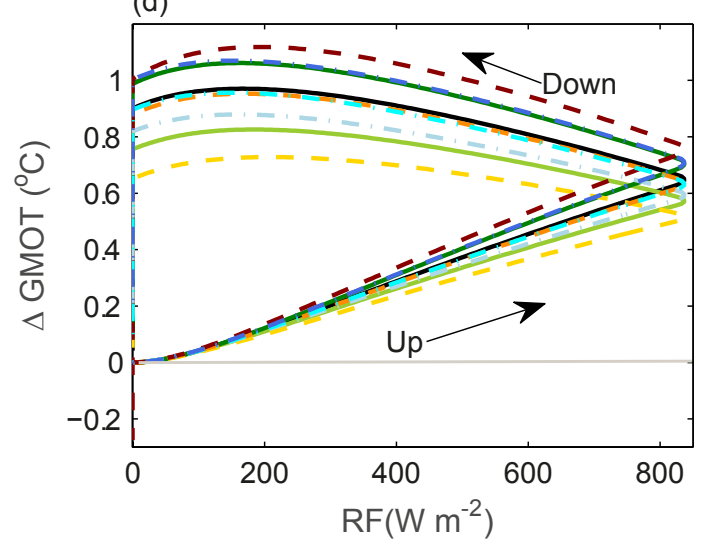

Figure 1. Changes in global mean surface air temperature (a), global mean thermosteric sea level (b), and global mean ocean temperature (c) relative to year 0 over time and change in GMOT versus radiative forcing (d). The solid vertical grey line in panels (a), (b), and (c) indicates the time of peak atmospheric $\mathrm{CO}_{2}$ concentration (quadrupling of pre-industrial levels, year 140). The dashed grey line in panel (b) and (c) indicates the time GMTSL and GMOT reach maximum values. The dot-dashed grey line in panel (c) is the time Figs. 2 and 3 refer to (year 1100). Horizontal grey lines mark zero.

\subsection{The effect of sub-grid-scale ocean mixing on sea level rise and its reversibility}

In this section we discuss the effect of different parameters for vertical ocean mixing on GMTSL rise and decline and identify the mechanisms that lead to the differences in GMTSL among model versions with different vertical diffusivities.

Under increasing atmospheric $\mathrm{CO}_{2}$ concentration, GMTSL and GMOT rise faster in model versions with higher vertical diffusivity (Fig. $1 \mathrm{~b}$ and c). Peak GMTSL, which occurs between year 208 and 227 (67 to 86 years after atmospheric $\mathrm{CO}_{2}$ starts declining), ranges between 0.45 and $0.80 \mathrm{~m}$. Similarly to the increase, GMTSL and GMOT also decrease faster under higher vertical ocean mixing, with exceptions for $k_{\mathrm{v}, \mathrm{B} \& \mathrm{~L}}$ high and $k_{\mathrm{v} \text {, tidal }} 0.45$ simulations (Fig. $1 \mathrm{~b}$ and c). In these simulations, the GMOT decrease rate is similar to the rate in model versions with lower vertical diffusivities. The causes for this behaviour will be discussed later in this section.
In most cases a higher decline rate of GMOT for a model version with higher vertical diffusivity results in a crossover of the GMOT curves (Fig. $1 \mathrm{~b}$ and c); for example, the $k_{\mathrm{v}, \mathrm{B} \& \mathrm{~L}}$ low simulation has slower ocean warming than the default simulation between year 0 and 900 . However, the rate of ocean temperature decline is higher in the default simulation than in the $k_{\mathrm{v}, \mathrm{B} \& \mathrm{~L}}$ low simulation, leading to a crossover of these two ocean temperature curves, and from around year 900 on the default simulation has lower ocean temperatures and thus a lower GMTSL.

This behaviour of faster GMOT increase and decline rates under higher mixing, including the crossover of the GMOT curves, can be explained with a two-layer model (Fig. 5a). This model consists of an upper layer (atmosphere and ocean surface layer) and a lower layer (deep ocean; Gregory, 2000; Bouttes et al., 2013). The upper layer is thin (depth $d_{\mathrm{u}} 100 \mathrm{~m}$ ) and responds immediately to changes in forcing because it has a small heat capacity. Due to its thickness (depth $d_{1}$ $2000 \mathrm{~m}$ ) the lower layer has a high heat capacity and thus provides the inertia of the ocean response. The heat flux between 
(a) Default mixing

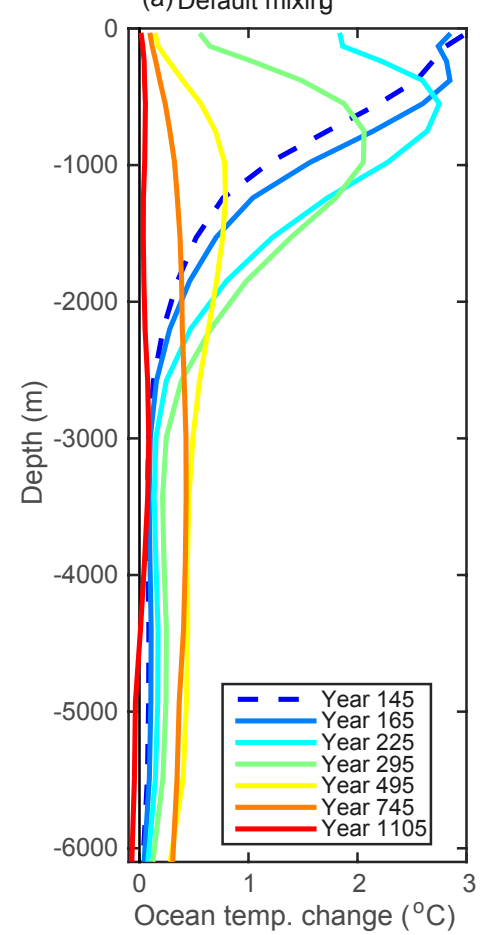

(b)

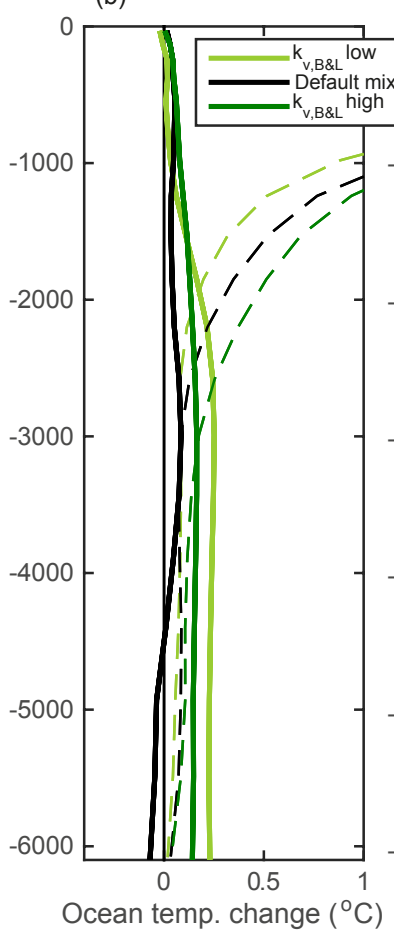

(c)

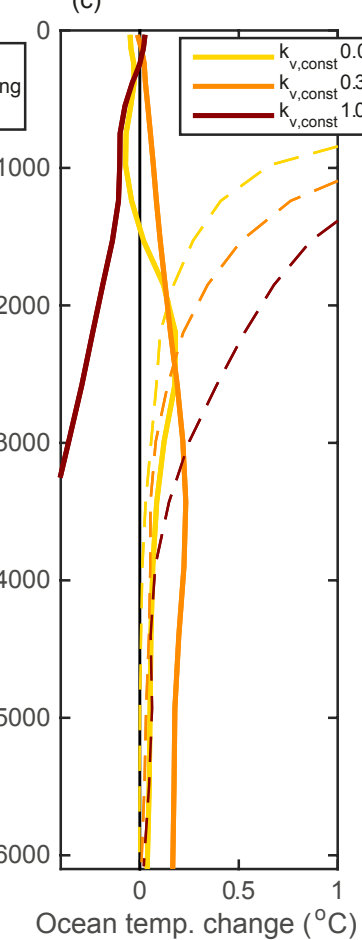

(d)

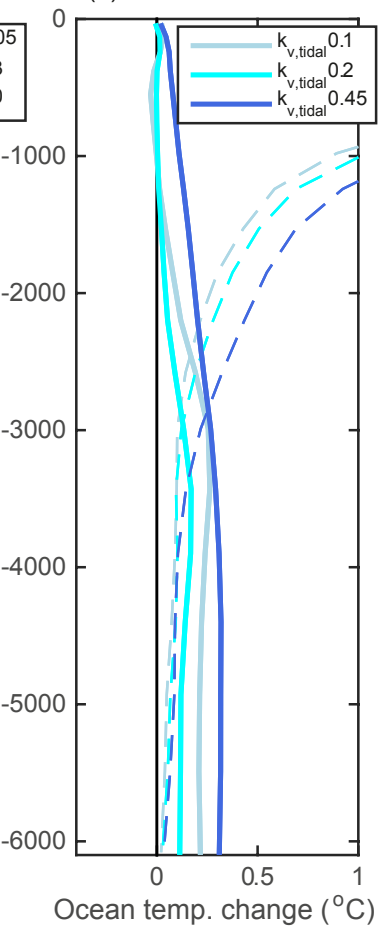

Figure 2. Depth profile of change in ocean temperature relative to year 0 for the model version with the default mixing setting for various points in time (a). Depth profile of change in ocean temperature relative to year 0 for model versions with different ocean mixing settings at year 140 (dashed curves, year of peak forcing) and year 1100 (solid curves) for Bryan and Lewis mixing scheme (b), constant mixing scheme (c), and tidal mixing scheme (d).

the upper and lower layer is proportional to the temperature difference between these layers and a thermal diffusion coefficient. The temperature for each layer ( $T_{\mathrm{u}}$ temperature upper layer, $T_{1}$ temperature lower layer) can be calculated using the following equations:

$c d_{\mathrm{u}} \frac{\mathrm{d} T_{\mathrm{u}}}{\mathrm{d} t}=\mathrm{RF}-c k \frac{\left(T_{\mathrm{u}}-T_{1}\right)}{0.5\left(d_{1}+d_{\mathrm{u}}\right)}-\lambda T_{\mathrm{u}}$,

$c d_{1} \frac{\mathrm{d} T_{1}}{\mathrm{~d} t}=c k \frac{\left(T_{\mathrm{u}}-T_{1}\right)}{0.5\left(d_{1}+d_{\mathrm{u}}\right)}$,

where $c=4.218 \times 10^{6} \mathrm{~J} \mathrm{~m}^{-3} \mathrm{~K}^{-1}$ is the volumetric heat capacity, $k=1 \times 10^{-4} \mathrm{~m}^{2} \mathrm{~s}^{-1}=1 \mathrm{~cm}^{2} \mathrm{~s}^{-1}$ is the thermal diffusivity between the layers, $\lambda=1.0 \mathrm{~W} \mathrm{~m}^{-2} \mathrm{~K}^{-1}$ is the climate feedback parameter, and $\mathrm{RF}\left(\mathrm{Wm}^{-2}\right)$ is the surface heat flux representing the external radiative forcing, which is prescribed according to a symmetric $1 \%$ yearly increase to quadrupling of pre-industrial $\mathrm{CO}_{2}$ levels and subsequent decrease in atmospheric $\mathrm{CO}_{2}$, as in the UVic ESCM simulations. Changes in mixing are achieved by changing the diffusivity $k$ between the layers in the range from $0.05 \times k$ to $1.0 \times$ $k$. This range is chosen to correspond to the range in vertical diffusivities in the UVic ESCM simulations $\left(k_{\mathrm{v}}\right.$, const $0.05-$ $1.0 \mathrm{~cm}^{2} \mathrm{~s}^{-1}$ ) that leads to the widest range in GMOT.

The temperature of the upper layer in the two-layer model reacts instantaneously to changes in the forcing (Fig. 5a). The temperature in the lower layer lags behind the radiative forcing and dominates the total temperature of the ocean (Fig. 5b and d) due to its very high heat capacity relative to the heat capacity of the upper layer. Therefore, ocean heat uptake or release can be approximated by the heat exchange between the layers, which is determined by the thermal diffusivity and the temperature gradient between the layers. Higher diffusivity between the layers enables faster heat exchange between the layers and faster heat uptake and release by the whole ocean as observed in the model (Fig. 5d). However, the temperature gradient between the layers is lowest for the model version with the highest diffusivity (Fig. 5c) implying diminished heat exchange between the layers and slower ocean heat uptake and release, which is the opposite of what is observed in the model. Therefore, it is the effect of the diffusion on ocean heat uptake that dominates over the effect of the vertical temperature gradient. This two-layer model also shows a similar hysteresis behaviour to the UVic ESCM (compare Figs. 1d and 5e).

One limitation of the two-layer model is that the heat capacity of the lower layer is very high, which results in very slow heat release from this layer. This effect is especially strong for very low diffusivity values (Fig. $5 \mathrm{~b}$ blue and red curves). For comparison, in a multi-layer model where heat is transferred step by step from one layer to the next, heat is 
(a) $k_{v, B \& L}$ low

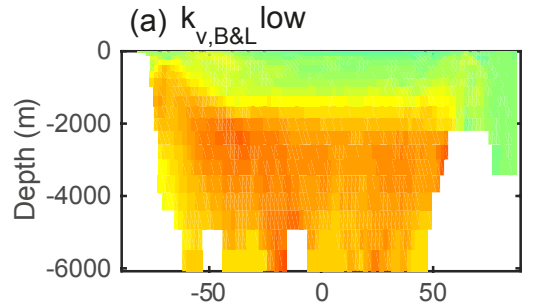

(d) $k_{v, \text { const }} 0.05$

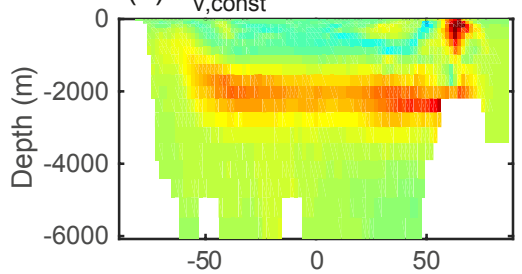

(g) $k_{v, \text { tidal }} 0.1$

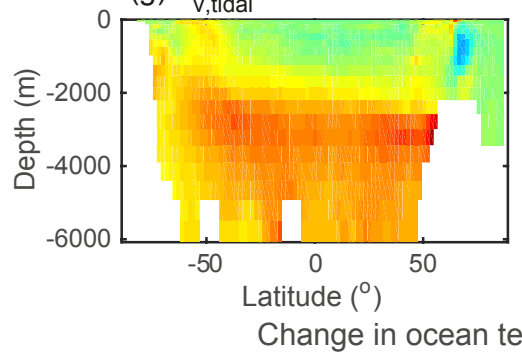

(b) Default mixing

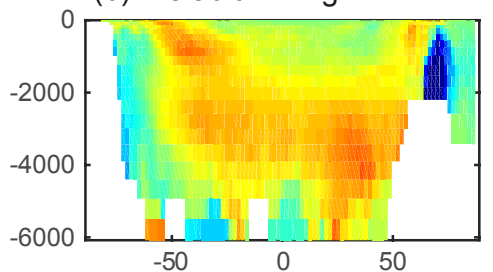

(e) $k_{\mathrm{v}, \text { const }} 0.3$

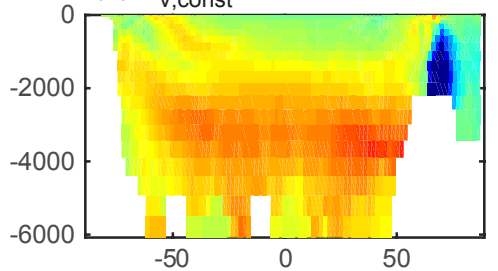

(h) $\mathrm{k}_{\mathrm{v}, \text { tidal }} 0.2$

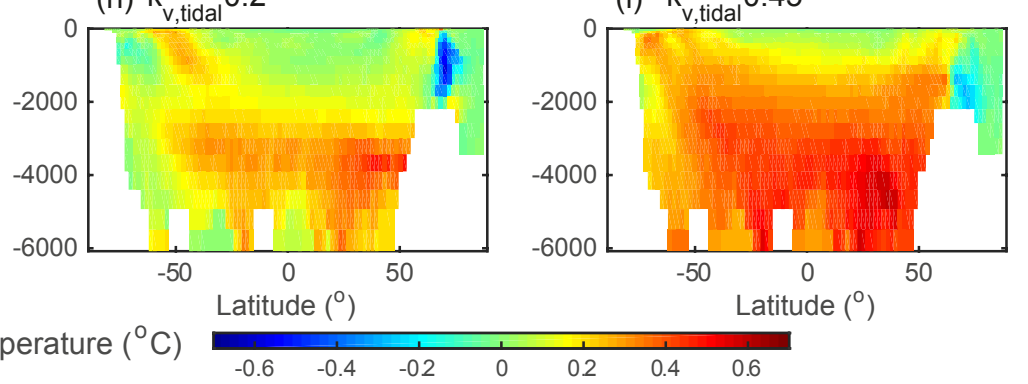

(c) $k_{v, B \& L}$ high

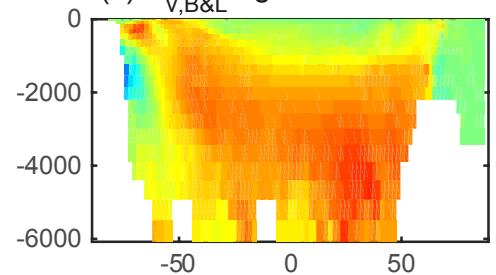

(f) $k_{v, \text { const }} 1.0$

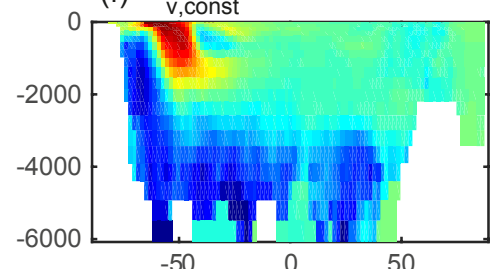

(i) $k_{v \text { tidal }} 0.45$

Figure 3. Zonal average change in ocean temperature for year 1100 relative to year 0 for the different model versions. Each row shows results for one mixing scheme (Bryan and Lewis mixing, constant mixing, tidal mixing in the first, second, and third row respectively), with vertical diffusivity increasing from left to right.

(a)

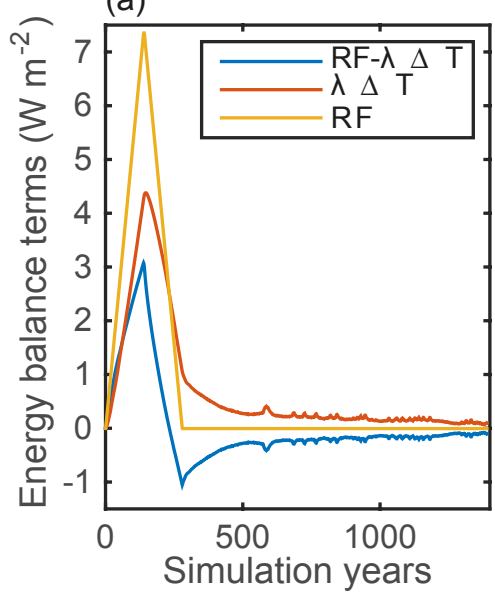



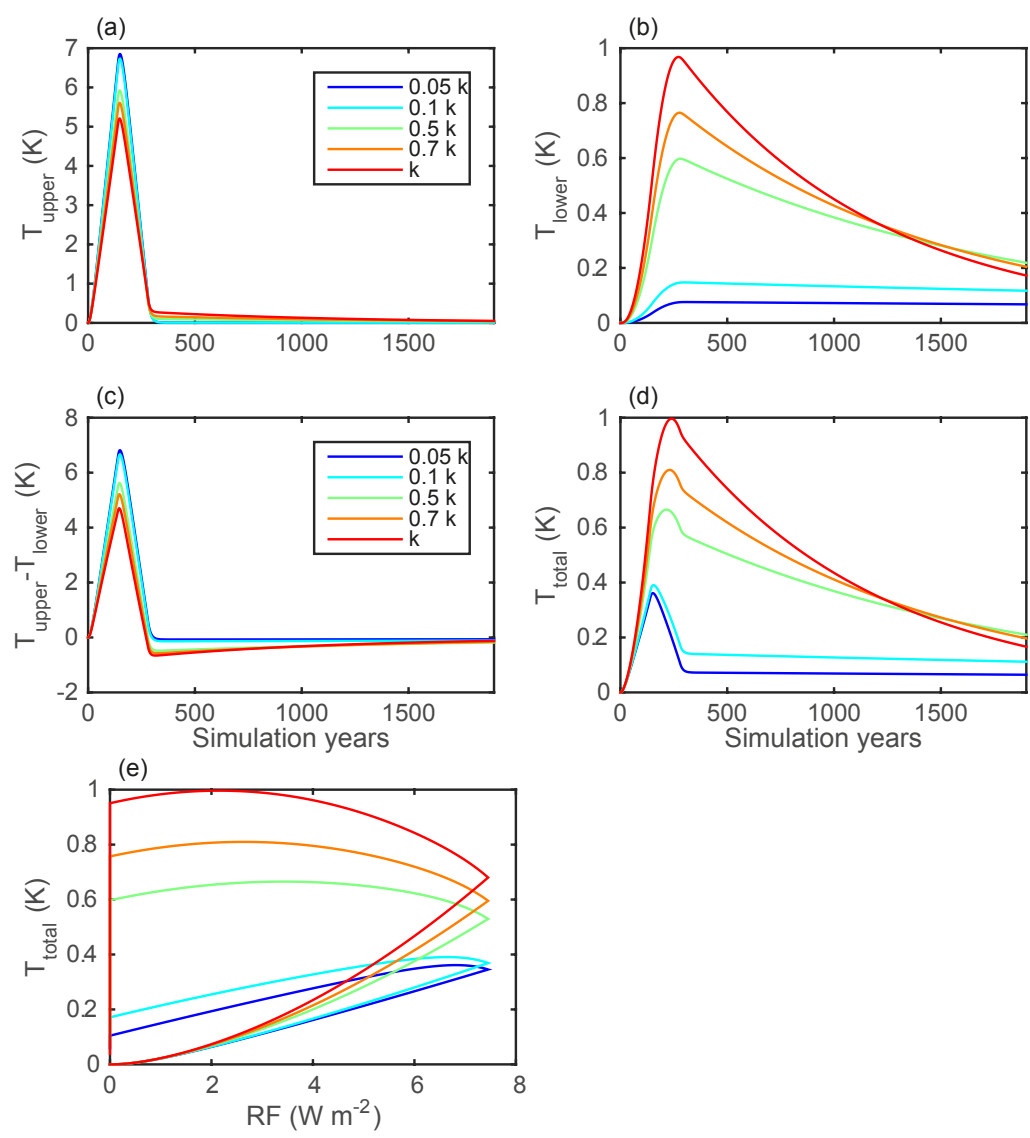

Figure 5. Temperature changes for the two-layer model: change in upper ( $\left.T_{\text {upper }}\right)(\mathbf{a})$ and lower layer temperature $T_{\text {lower }}(\mathbf{b})$, difference in the temperature between the layers (c), change in total temperature (d, calculated as average of $T_{\text {upper }}$ and $T_{\text {lower }}$ weighted by the layer depth), and change in total temperature versus radiative forcing (e). $k=1 \mathrm{~cm}^{2} \mathrm{~s}^{-1}$ is the thermal diffusivity between the layers.

not include a representation of the meridional overturning circulation, which intensifies in the UVic ESCM simulations in both the Atlantic Ocean and Southern Ocean after radiative forcing returns to zero and leads to stronger heat release. Due to these two shortcomings the decline in ocean temperature is much slower in the two-layer model than in the UVic ESCM, and the two-layer model simulations have to be extended for 1000 years more than the UVic ESCM simulations to observe a crossover of the ocean temperature curves.

Generally, the initial (pre-industrial) meridional overturning circulation in both the Atlantic Ocean and Southern Ocean increases as vertical diffusivity increases between the UVic ESCM model versions (Fig. 6a and c). In addition, the response of the meridional overturning circulation to the radiative forcing also differs among model versions. These differences in the overturning response lead to divergences between the results of UVic ESCM simulations and two-layer ocean model simulations, as will be discussed in the following. The UVic ESCM simulations diverge from the twolayer ocean model behaviour for two model version pairs. The model version with default ocean mixing setting and the $k_{\mathrm{v}, \mathrm{B} \& \mathrm{~L}}$ high model version have different vertical diffusivi- ties but a similar GMTSL decline rate. The same is true for the $k_{\mathrm{v} \text {, tidal }} 0.2$ and the $k_{\mathrm{v} \text {, tidal }} 0.45$ model versions. For each model version pair, the uptake of heat is faster for the model version with higher vertical diffusivity but the rate of heat release is approximately the same. This similar ocean heat release rate is likely caused by stronger intensification of the overturning circulation in both the Atlantic and Southern oceans in response to the declining radiative forcing in the simulations with lower vertical diffusivity (i.e. default mix-

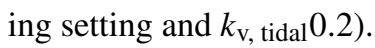

The globally averaged vertical ocean temperature profiles illustrate that higher mixing does not always entail a stronger decline in ocean temperatures (Fig. 2b and d). At year 140 (year of peak forcing), for the simulations with Bryan and Lewis mixing scheme (default mixing setting, $k_{\mathrm{v}, \mathrm{B} \& \mathrm{~L}}$ low and high) and the tidal mixing scheme $\left(k_{\mathrm{v}, \text { tidal }}\right)$, the temperature change relative to year 0 at the surface and mid-ocean is higher for simulations with higher vertical diffusivities. However, at year 1100 the default mixing and $k_{\mathrm{v} \text {, tidal }} 0.2 \mathrm{sim}$ ulations show the lowest ocean temperature below a depth of around $1100 \mathrm{~m}$. Interestingly, in those cases the deep ocean has also cooled more than the mid-ocean, probably induced 

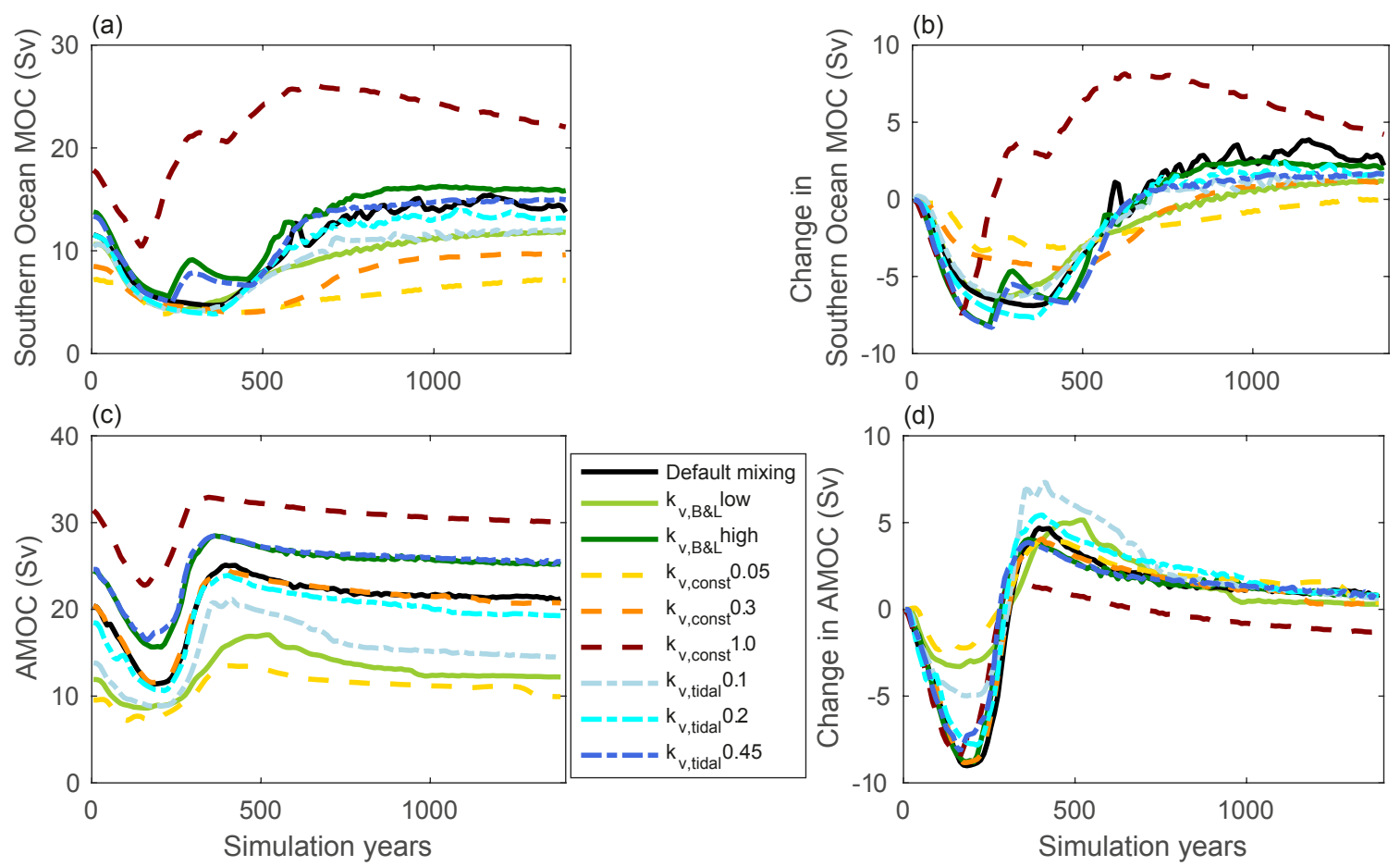

Figure 6. Meridional overturning circulation (MOC) in the Southern Ocean (a) and in the North Atlantic (c). Change in the MOC relative to year 0 in the Southern Ocean (b) and in the North Atlantic (d). The MOC in the Southern Ocean and the North Atlantic are computed from the minimum and maximum respectively of the zonally averaged stream function below a depth of $400 \mathrm{~m}$. The stream function is calculated from decadal averages of the meridional velocity. The maximum of the zonally averaged stream function occurs between 30 and $40^{\circ} \mathrm{N}$ and the minimum occurs between 0 and $70^{\circ} \mathrm{S}$.

by increased meridional overturning circulation (MOC) in the Southern Ocean. For the tidal mixing scheme, both simulations with the lower mixing setting $\left(k_{\mathrm{v}, \text { tidal }} 0.1\right.$ and 0.2$)$

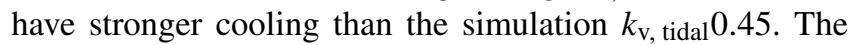
discussion of the overturning circulation and especially its response to the declining radiative forcing will give further insights into this behaviour.

Both the Atlantic Meridional Overturning Circulation (AMOC) and MOC in the Southern Ocean decline in response to increased atmospheric $\mathrm{CO}_{2}$ concentration and the associated global warming (Fig. 6a and c). The AMOC response to global warming has been well studied (Stocker and Schmittner, 1997; Rahmstorf, 2006; Meehl et al., 2007; Liu et al., 2017), and the decline in the AMOC under warming is due to warming and freshening of North Atlantic surface waters (Rahmstorf, 2006). The AMOC increases again in a delayed response to the decrease in radiative forcing (Fig. 6c). This decrease leads to cooling of surface waters and also an increase in sea ice formation that increases surface water density and thus deep water formation. The AMOC even overshoots its pre-industrial strength (Fig. 6d) due to a build-up of salinity in the subtropical gyre in the North Atlantic while the AMOC is weaker (Wu et al., 2011). When the AMOC strengthens again as a response to declining surface temperature this salinity anomaly is advected northward, which re- sults in denser water in the deep water formation regions and an intensified AMOC. This AMOC overshoot has been linked to an increased rate of ocean heat release (Bouttes et al., 2015) and thus a stronger GMTSL decline. Earlier studies (Knutti and Stocker, 2000; Levermann et al., 2005) found a slow increase (over several millennia) of global mean sea level after a shut down of the AMOC because the reduction of the surface temperature induced by the AMOC shutdown reduces the radiation lost to space and thereby increases ocean heat uptake. A rapid regional thermosteric sea level rise in the North Atlantic with thermosteric sea level decrease in the Southern Ocean is also shown by (Levermann et al., 2005). This slow increase of global sea level under AMOC shutdown is in contrast to the mechanism we propose whereby GMTSL rises less with a weaker AMOC. However, the mechanism between a slowdown of the AMOC and a complete shutdown could be different because a slightly weaker AMOC does not induce such strong changes in surface temperature. Declining MOC in the Southern Ocean as response to anthropogenic climate change has been seen in models and observational data (Purkey and Johnson, 2012), but to our knowledge the causes for this response have not been explored. MOC in the Southern Ocean increases as a delayed response to the decreasing radiative forcing (Fig. 6a), likely due to surface cooling and increased sea ice formation, 
and it also intensifies above pre-industrial levels (Fig. 6b). However, this intensification is much smaller and slower than the AMOC overshoot. Further investigation is needed to fully explain the processes that cause this intensification.

Both AMOC and MOC in the Southern Ocean overshoot/intensify more strongly in the model versions with lower mixing setting (i.e. in the model version with default mixing relative to $k_{\mathrm{v}, \mathrm{B} \& \mathrm{~L}}$ high, and $k_{\mathrm{v}, \text { tidal }} 0.1$ and 0.2 relative to $k_{\mathrm{v}, \text { tidal }} 0.45$; Fig. $6 \mathrm{~b}$ and d), which leads to faster heat release as the exchange between deep/bottom waters and surface waters is enhanced. This intensification in overturning circulation likely offsets the slower heat exchange between upper and deeper ocean in the model version with lower mixing (i.e. default mixing setting and $k_{\mathrm{v}, \text { tidal }} 0.2$ ). The cooling effect on the deep and bottom waters from stronger-than-preindustrial AMOC and MOC in the Southern Ocean is also evident in the zonally averaged ocean temperature changes (Fig. 3), where the simulations with default ocean mixing

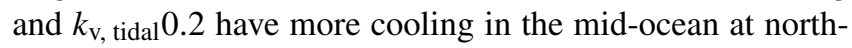
ern high latitudes and the deep ocean at southern high lat-

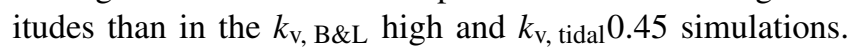
The deep ocean cooling is less pronounced in the $k_{\mathrm{v} \text {, tidal }} 0.2$ case. Also the $k_{\mathrm{v} \text {, tidal }} 0.1$ shows very strong AMOC overshoot (Fig. 6d), which together with the lower heat uptake during the increasing forcing phase results in stronger cooling than

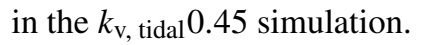

A special case is the $k_{\mathrm{v} \text {, const }} 1.0$ simulation, which has the highest vertical mixing of all simulations. Here, the GMOT and thus GMTSL decline below pre-industrial levels (at year 830) implying that more heat is being released than initially entered the ocean. This strong cooling is likely linked to strong intensification of MOC in the Southern Ocean under this very high mixing setting (Fig. 6b, red curve). This assumption is supported by strong cooling in the Southern Ocean along the path of MOC in the Southern Ocean (Fig. 3f). The intensification of MOC in the Southern Ocean is likely enabled by a deep convection cell that persists in this model version for multiple centuries in the Southern Ocean. Due to the high vertical mixing in this model version, the deeper ocean is relatively warm (compared to other model versions), which causes instabilities in the Southern Ocean, where surface waters are very cold and convection cells form. While atmospheric $\mathrm{CO}_{2}$ increases, these cells only persist for a decade or less and therefore do not have a significant effect on ocean heat uptake and GMTSL. However, when atmospheric $\mathrm{CO}_{2}$ and thus GMSAT decline, the surface ocean cools, which reinforces deep convection and enables the convection cell to persist for centuries. High vertical mixing is not observed at all depths, and therefore this model version and the strong decline in GMTSL may not be realistic.

In most model versions, a warming tongue just north of the Antarctic Circumpolar Current that persists until the end of the simulations is evident (Fig. 3). This agrees with observations and model simulations, which show strong ocean heat uptake of anthropogenic-induced warming in the Southern
Ocean along the downwelling branch of the residual MOC (Liu et al., 2016). The majority of this heat is stored around $45^{\circ} \mathrm{S}$, where surface waters sink down and travel northward (Armour et al., 2016).

\section{Discussion and conclusions}

In this study the reversibility of thermosteric sea level rise in response to a symmetric increase and decrease in atmospheric $\mathrm{CO}_{2}$ concentration is examined. Furthermore, the sensitivity of this reversibility to sub-grid-scale ocean mixing is investigated, which also gives further insight into the role of ocean circulation in this reversibility. Different versions of the UVic ESCM 2.9, which differ in the parametrization of vertical sub-grid-scale ocean mixing, are forced with a $1 \%$ yearly increase in atmospheric $\mathrm{CO}_{2}$ concentration until a quadrupling of pre-industrial levels is reached, followed by a $1 \%$ yearly decrease in $\mathrm{CO}_{2}$ to pre-industrial and constant pre-industrial $\mathrm{CO}_{2}$ concentration thereafter. Such a strong decline in atmospheric $\mathrm{CO}_{2}$ concentration can only be realized with net $\mathrm{CDR}$ (i.e. net atmospheric $\mathrm{CO}_{2}$ removal). The CDR required to achieve a $1 \%$ yearly decline in atmospheric $\mathrm{CO}_{2}$ are likely unfeasible with current technologies (Boucher et al., 2012; Tokarska and Zickfeld, 2015), and the results shown in this study are therefore conservative. Thus, also the fast change from positive $\mathrm{CO}_{2}$ emissions to net CDR that is needed to achieve the turn from a $1 \%$ yearly increase to a $1 \%$ yearly decrease in $\mathrm{CO}_{2}$ is technologically unlikely. CDR rates needed to achieve a $1 \%$ yearly decline are as large as $20 \mathrm{PgCyr}^{-1}$, whereas for comparison, removal rates for RCP2.6 do not exceed $1.6 \mathrm{PgCyr}^{-1}$ in the UVic ESCM default ocean mixing version. Technologically feasible CDR rates have been estimated to range between 2.7 and 9.5 $\mathrm{Pg} \mathrm{Cyr}^{-1}$ (Tavoni and Socolow, 2013; National Research Council, 2015)

We find that thermosteric sea level rise is not reversible on human timescales (decades to a century) as it continues for 80 years after atmospheric $\mathrm{CO}_{2}$ concentration starts declining and drops only slowly thereafter. The decline of GMTSL is much slower than the rise due to the thermal inertia of the ocean, which is expressed by a warming signal in the deeper ocean that persists for almost a millennium after atmospheric $\mathrm{CO}_{2}$ concentration is restored to pre-industrial levels. Furthermore, GMTSL does not revert to pre-industrial values by the end of the simulations (1120 years after atmospheric $\mathrm{CO}_{2}$ concentration is restored to pre-industrial levels). The release of heat by the ocean, and thus a declining GMTSL, is explained by invoking a 0-D EBM where the rate of GMTSL rise is linked to radiative forcing and a term representing radiative damping to space. This model shows that a declining GMTSL is enabled by radiative forcing being lower than the change in GMSAT scaled by the climate feedback parameter.

Generally, sea level rise and decline rates in response to rising and declining atmospheric $\mathrm{CO}_{2}$ increase with higher 
vertical diffusivity, which can be explained with a simple two-layer atmosphere-ocean model with diffusion of heat between a thin upper layer and a deep lower layer. Exceptions to this behaviour in the UVic ESCM simulations are linked to a strengthening of the meridional overturning circulation beyond pre-industrial values in the North Atlantic and the Southern Ocean after recovering from a decline induced by the increasing radiative forcing. Generally, this intensification in meridional overturning circulation beyond preindustrial values is stronger in model versions with lower vertical diffusivity. In some cases this intensification is so large that it offsets the effect of decreased vertical diffusivity and GMTSL decline rates are similar among model versions with different diffusivity values. Stronger MOC in the Southern Ocean and the North Atlantic increases the exchange of heat between the upper and the deeper ocean, and the intensification of this deep and bottom water formation beyond their pre-industrial levels increases the release of heat from the ocean. In particular, the intensification of MOC in the Southern Ocean results in cooling of the deep ocean after radiative forcing has returned to zero.

Limitations of the research presented here are that the model used (UVic ESCM 2.9) does not include an interactive ice sheet component and no interactive representation of cloud feedbacks. The lack of an interactive ice sheet component means that sea level rise and possible decline from the melting and possibly regrowing ice sheets in response to the increase and decline in radiative forcing is not included. The contribution to sea level rise from melting ice sheets is projected to become dominant in the future and reversibility of sea level rise from ice sheet melting would be delayed due to their long response timescales and possible threshold behaviour (Robinson et al., 2012; Church et al., 2013). However, there are large uncertainties for these contributions due to incomplete understanding of ice sheet dynamics (Church et al., 2013). The lack of interactive representation of cloud feedbacks affects ocean heat uptake as investigations with AOGCMs have shown that changes in cloud cover enhance the atmospheric cooling effect from changes in the location of ocean heat uptake induced by changes in ocean circulation due to climate change (Trossman et al., 2016). Thus the model used here might underestimate the effect of changes in ocean circulation on ocean heat uptake under increasing atmospheric $\mathrm{CO}_{2}$. Whether this interaction among ocean heat uptake, changes in ocean circulation, and cloud cover also takes place when the changes in ocean circulation are induced by changes in ocean mixing, and how this link evolves under declining $\mathrm{CO}_{2}$ concentration, is unclear.

These limitations are unlikely to affect the robustness of the result that thermosteric sea level rise is not reversible on human timescales. Including the contribution from ice sheets to sea level would make sea level rise even less reversible due to the very long response timescales of ice sheet dynamics. Significant changes in the response time of thermosteric sea level changes caused by including dynamic cloud feedbacks are unlikely as the associated effect on ocean heat uptake is very small (Trossman et al., 2016).

This study shows that ocean thermal expansion induced by rising atmospheric $\mathrm{CO}_{2}$ concentration does not return to pre-industrial levels for at least a millennium after $\mathrm{CO}_{2}$ concentration is restored to pre-industrial levels, irrespective of the choice of vertical diffusivity. It has been argued that models are too diffusive relative to the real ocean (Hansen et al., 2011). Thus a less diffusive ocean would imply a lower GMTSL rise at first, but sea level rise would persist long after $\mathrm{CO}_{2}$ concentration is restored to pre-industrial levels. However, it should be noted that simply increasing the diffusivity in climate models is not possible as a highly diffusive ocean is needed to properly parameterize unresolved eddies that close the meridional overturning circulation (Marshall and Speer, 2012). The time of reversal of sea level rise to pre-industrial levels would likely be prolonged further if sea level rise from melting ice sheets were taken into account, as ice sheets respond on even longer timescales than ocean heat uptake and their contribution to sea level rise is projected to increase in the future (Church et al., 2013; Clark et al., 2016).

We conclude that sea level rise from thermal expansion is not reversible even under strong decreases in atmospheric $\mathrm{CO}_{2}$ on timescales relevant to human civilization.

Code and data availability. The code for UVic ESCM version 2.9 can be found at http://climate.uvic.ca/model/2.9/ (UVic ESCM Developers Group, 2018). The model data, including description of model settings for the different model versions, can be found at https://doi.org/10.20383/101.021 (Ehlert and Zickfeld, 2018).

\section{The Supplement related to this article is available online at https://doi.org/10.5194/esd-9-197-2018-supplement.}

Author contributions. DE designed, executed, and analysed the model simulations, interpreted the simulation results, and wrote the manuscript. KZ conceived the research, assisted in data analysis and interpretation, and edited the manuscript.

Special issue statement. This article is part of the special issue "The Earth system at a global warming of $1.5^{\circ} \mathrm{C}$ and $2.0^{\circ} \mathrm{C}$ ". It does not belong to a conference.

Acknowledgements. Kirsten Zickfeld acknowledges support from the Natural Sciences and Engineering Research Council of Canada (NSERC) Discovery Grant Program. This research was enabled in part by computing resources provided by Westgrid and Compute Canada. We thank four anonymous referees for their helpful feedback. 
Edited by: Yun Liu

Reviewed by: four anonymous referees

\section{References}

Armour, K. C., Marshall, J., Scott, J. R., Donohoe, A., and Newsom, E. R.: Southern Ocean warming delayed by circumpolar upwelling and equatorward transport, Nat. Geosci., 9, 549-554, 2016.

Boucher, O., Halloran, P. R., Burke, E. J., Doutriaux-Boucher, M., Jones, C. D., Lowe, J., Ringer, M. A., Robertson, E., and $\mathrm{Wu}$, P.: Reversibility in an Earth System model in response to $\mathrm{CO}_{2}$ concentration changes, Environ. Res. Lett., 7, 024013, https://doi.org/10.1088/1748-9326/7/2/024013, 2012.

Bouttes, N., Gregory, J. M., and Lowe, J. A.: The Reversibility of Sea Level Rise, J. Climate, 26, 2502-2513, https://doi.org/10.1175/JCLI-D-12-00285.1, 2013.

Bouttes, N., Good, P., Gregory, J. M., and Lowe, J. A.: Nonlinearity of ocean heat uptake during warming and cooling in the FAMOUS climate model, Geophys. Res. Lett., 42, 2409-2416, https://doi.org/10.1002/2014GL062807, 2015.

Bryan, K. and Lewis, L.: A water mass model of the world ocean, J. Geophys. Res., 84, 2503-2517, 1979.

Church, J., Clark, P., Cazenave, A., Gregory, J., Jevrejeva, S., Levermann, A., Merrifield, M., Milne, G., Nerem, R., Nunn, P., Payne, A., Pfeffer, W., Stammer, D., and Unnikrishnan, A.: Sea Level Change, in: Climate Change 2013: The Physical Science Basis, Contribution of Working Group I to the Fifth Assessment Report of the Intergovernmental Panel on Climate Change, book section 13, edited by: Stocker, T., Qin, D., Plattner, G.-K., Tignor, M., Allen, S., Boschung, J., Nauels, A., Xia, Y., Bex, V., and Midgley, P., Cambridge University Press, Cambridge, United Kingdom and New York, NY, USA, 1137-1216, available at: www.climatechange2013.org, 2013.

Clark, P. U., Shakun, J. D., Marcott, S. A., Mix, A. C., Eby, M., Kulp, S., Levermann, A., Milne, G. A., Pfister, P. L., Santer, B. D., Schrag, D. P., Solomon, S., Stocker, T. F., Strauss, B. H., Weaver, A. J., Winkelmann, R., Archer, D., Bard, E., Goldner, A., Lambeck, K., Pierrehumbert, R. T., and Plattner, G.-K.: Consequences of twenty-first-century policy for multi-millennial climate and sea-level change, Nat. Clim. Change, 6, 360-369, https://doi.org/10.1038/nclimate2923, 2016.

Collins, M., Knutti, R., Arblaster, J., Dufresne, J.-L., Fichefet, T., Friedlingstein, P., Gao, X., Gutowski, W., Johns, T., Krinner, G., Shongwe, M., Tebaldi, C., Weaver, A., and Wehner, M.: Long-term Climate Change: Projections, Commitments and Irreversibility, in: Climate Change 2013: The Physical Science Basis, Contribution of Working Group I to the Fifth Assessment Report of the Intergovernmental Panel on Climate Change, book section 12, edited by: Stocker, T., Qin, D., Plattner, G.-K., Tignor, M., Allen, S., Boschung, J., Nauels, A., Xia, Y., Bex, V., and Midgley, P., Cambridge University Press, Cambridge, United Kingdom and New York, NY, USA, 1029-1136, available at: www.climatechange2013.org, 2013.

Cox, P. M.: Description of the TRIFFID dynamic global vegetation model: Hadley Centre Technical Note 24, Hadley Centre technical note 24, Hadley Centre, Met Office, Berks, UK, 2001.
Cox, P. M., Betts, R. A., Bunton, C. B., Essery, R. L. H., Rowntree, P. R., and Smith, J.: The impact of new land surface physics on the GCM simulation of climate and climate sensitivity, Clim. Dynam., 15, 183-203, https://doi.org/10.1007/s003820050276, 1999.

Eby, M., Zickfeld, K., Montenegro, A., Archer, D., Meissner, K. J., and Weaver, A. J.: Lifetime of anthropogenic climate change: millennial time scales of potential $\mathrm{CO}_{2}$ and surface temperature Perturbations, J. Climate, 22, 2501-2511, https://doi.org/10.1175/2008JCLI2554.1, 2009.

Eby, M., Weaver, A. J., Alexander, K., Zickfeld, K., Abe-Ouchi, A., Cimatoribus, A. A., Crespin, E., Drijfhout, S. S., Edwards, N. R., Eliseev, A. V., Feulner, G., Fichefet, T., Forest, C. E., Goosse, H., Holden, P. B., Joos, F., Kawamiya, M., Kicklighter, D., Kienert, H., Matsumoto, K., Mokhov, I. I., Monier, E., Olsen, S. M., Pedersen, J. O. P., Perrette, M., Philippon-Berthier, G., Ridgwell, A., Schlosser, A., Schneider von Deimling, T., Shaffer, G., Smith, R. S., Spahni, R., Sokolov, A. P., Steinacher, M., Tachiiri, K., Tokos, K., Yoshimori, M., Zeng, N., and Zhao, F.: Historical and idealized climate model experiments: an intercomparison of Earth system models of intermediate complexity, Clim. Past, 9, 11111140, https://doi.org/10.5194/cp-9-1111-2013, 2013.

Ehlert, D. and Zickfeld, K.: Model data "Irreversible ocean thermal expansion under carbon dioxide removal", https://doi.org/10.20383/101.021, 2018.

Ehlert, D., Zickfeld, K., Eby, M., and Gillett, N.: The Sensitivity of the Proportionality between Temperature Change and Cumulative $\mathrm{CO}_{2}$ Emissions to Ocean Mixing, J. Climate, 30, 2921-2935, https://doi.org/10.1175/JCLI-D-16-0247.1, 2017.

Fuss, S., Jones, C. D., Kraxner, F., Peters, G. P., Smith, P., Tavoni, M., van Vuuren, D. P., Canadell, J. G., Jackson, R. B., Milne, J., Moreira, J. R., Nakicenovic, N., Sharifi, A., and Yamagata, Y.: Research priorities for negative emissions, Environ. Res. Lett., 11, 115007, https://doi.org/10.1088/17489326/11/11/115007, 2016.

Gent, P. R. and McWilliams, J. C.: Isopycnal mixing in ocean circulation models, J. Phys. Oceanogr., 20, 150-155, https://doi.org/10.1175/15200485(1990)020<0150:IMIOCM>2.0.CO;2, 1990.

Geoffroy, O., Saint-Martin, D., Olivié, D. J. L., Voldoire, A., Bellon, G., and Tytéca, S.: Transient climate response in a two-layer energy-balance model, Part I: Analytical solution and parameter calibration using CMIP5 AOGCM experiments, J. Climate, 26, 1841-1857, https://doi.org/10.1175/JCLI-D-12-00195.1, 2013.

Gillett, N. P., Arora, V. K., Zickfeld, K., Marshall, S. J., and Merryfield, W. J.: Ongoing climate change following a complete cessation of carbon dioxide emissions, Nat. Geosci., 4, 83-87, https://doi.org/10.1038/ngeo1047, 2011.

Goes, M., Urban, N. M., Tonkonojenkov, R., Haran, M., Schmittner, A., and Keller, K.: What is the skill of ocean tracers in reducing uncertainties about ocean diapycnal mixing and projections of the Atlantic Meridional Overturning Circulation?, J. Geophys. Res.-Oceans, 115, C12006, https://doi.org/10.1029/2010JC006407, 2010.

Gregory, J. M.: Vertical heat transports in the ocean and their effect on time-dependent climate change, Clim. Dynam., 16, 501-515, https://doi.org/10.1007/s003820000059, 2000.

Hansen, J., Sato, M., Kharecha, P., and von Schuckmann, K.: Earth's energy imbalance and implications, Atmos. Chem. Phys., 
11, 13421-13449, https://doi.org/10.5194/acp-11-13421-2011, 2011.

Knutti, R. and Stocker, T. F.: Influence of the thermohaline circulation on projected sea level rise, J. Climate, 13, 1997-2001, https://doi.org/10.1175/15200442(2000)013<1997:IOTTCO>2.0.CO;2, 2000.

Levermann, A., Griesel, A., Hofmann, M., Montoya, M., and Rahmstorf, S.: Dynamic sea level changes following changes in the thermohaline circulation, Clim. Dynam., 24, 347-354, https://doi.org/10.1007/s00382-004-0505-y, 2005.

Liu, W., Xie, S.-P., and Lu, J.: Tracking ocean heat uptake during the surface warming hiatus, Nat. Commun., 7, 10926, https://doi.org/10.1038/ncomms10926, 2016.

Liu, W., Xie, S.-P., Liu, Z., and Zhu, J.: Overlooked possibility of a collapsed Atlantic Meridional Overturning Circulation in warming climate, Science Advances, 3, e1601666, https://doi.org/10.1126/sciadv.1601666, 2017.

MacDougall, A. H.: Reversing climate warming by artificial atmospheric carbon-dioxide removal: can a Holocene-like climate be restored?, Geophys. Res. Lett., 40, 5480-5485, https://doi.org/10.1002/2013GL057467, 2013.

MacDougall, A. H., Zickfeld, K., Knutti, R., and Matthews, H. D.: Sensitivity of carbon budgets to permafrost carbon feedbacks and non-CO 2 forcings, Environ. Res. Lett., 10, 125003, http://stacks. iop.org/1748-9326/10/i=12/a=125003, 2015 .

Marshall, J. and Speer, K.: Closure of the meridional overturning circulation through Southern Ocean upwelling, Nat. Geosci., 5, 171-180, 2012.

Matthews, H. D. and Caldeira, K.: Stabilizing climate requires near-zero emissions, Geophys. Res. Lett., 35, L04705, https://doi.org/10.1029/2007GL032388, 2008.

Matthews, H. D. and Zickfeld, K.: Climate response to zeroed emissions of greenhouse gases and aerosols, Nat. Clim. Change, 2, 338-341, https://doi.org/10.1038/nclimate1424, 2012.

Meehl, G., Stocker, T. F., Collins, W., Friedlingstein, P., Gaye, A., Gregory, J., Kitoh, A., Knutti, R., Murphy, J., Noda, A., Raper, S. C. B., Watterson, I., Weaver, A., and Zhao, Z.-C.: Global Climate Projections, in: Climate Change 2007: Contribution of Working Group I to the Fourth Assessment Report of the Intergovernmental Panel on Climate Change, chap. 10, edited by: Solomon, S., Qin, D., Manning, M., Chen, Z., Marquis, M., Averyt, K. B., Tignor, M., and Miller, H. L., Cambridge University Press, Cambridge, United Kingdom and New York, NY, USA, 747-846, available at: http://www.ipcc.ch/pdf/ assessment-report/ar4/wg1/ar4-wg1-chapter10.pdf, 2007.

Meinshausen, M., Smith, S. J., Calvin, K., Daniel, J. S., Kainuma, M. L. T., Lamarque, J.-F., Matsumoto, K., Montzka, S. A., Raper, S. C. B., Riahi, K., Thomson, A., Velders, G. J. M., and Vuuren, D. P.: The RCP greenhouse gas concentrations and their extensions from 1765 to 2300, Climatic Change, 109, 213-241, https://doi.org/10.1007/s10584-0110156-z, 2011.

Meissner, K. J., Weaver, a. J., Matthews, H. D., and Cox, P. M.: The role of land surface dynamics in glacial inception: a study with the UVic Earth System Model, Clim. Dynam., 21, 515-537, https://doi.org/10.1007/s00382-003-0352-2, 2003.

National Research Council: Climate Intervention: Carbon Dioxide Removal and Reliable Sequestration, The National Academies Press, Washington, DC, 2015.
Paris Agreement: United Nations Framework Convention on Climate Change, Paris Agreement, http://unfccc.int/files/ essential_background/convention/application/pdf/english_ paris_agreement.pdf, last access: 1 February 2016, 2015.

Peters, G. P., Andrew, R. M., Solomon, S., and Friedlingstein, P.: Measuring a fair and ambitious climate agreement using cumulative emissions, Environ. Res. Lett., 10, 105004, https://doi.org/10.1088/1748-9326/10/10/105004, 2015.

Purkey, S. G. and Johnson, G. C.: Global contraction of antarctic bottom water between the 1980s and 2000s, J. Climate, 25 , 5830-5844, https://doi.org/10.1175/JCLI-D-11-00612.1, 2012.

Rahmstorf, S.: Thermohaline Ocean Circulation, in: Encyclopedia of Quaternary Sciences, edited by: Elias, S. A., Elsevier, Amsterdam, 1-10, 2006.

Rahmstorf, S.: A semi-empirical approach to projecting future sea-level rise, Science, 315, 368-370, https://doi.org/10.1126/science.1135456, 2007.

Robinson, A., Calov, R., and Ganopolski, A.: Multistability and critical thresholds of the Greenland ice sheet, Nat. Clim. Change, 2, 429-432, https://doi.org/10.1038/nclimate1449, 2012.

Rogelj, J., den Elzen, M., Höhne, N., Fransen, T., Fekete, H., Winkler, H., Schaeffer, R., Sha, F., Riahi, K., and Meinshausen, M.: Paris agreement climate proposals need a boost to keep warming well below $2{ }^{\circ} \mathrm{C}$, Nature, 534, 631-639, https://doi.org/10.1038/nature18307, 2016a.

Ross, A., Matthews, H. D., Schmittner, A., and Kothavala, Z.: Assessing the effects of ocean diffusivity and climate sensitivity on the rate of global climate change, Tellus B, 64, 1-10, https://doi.org/10.3402/tellusb.v64i0.17733, 2012.

Schmittner, A., Oschlies, A., Giraud, X., Eby, M., and Simmons, H. L.: A global model of the marine ecosystem for long-term simulations: Sensitivity to ocean mixing, buoyancy forcing, particle sinking, and dissolved organic matter cycling, Global Biogeochem. Cy., 19, GB3004, https://doi.org/10.1029/2004GB002283, 2005.

Schmittner, A., Urban, N. M., Keller, K., and Matthews, D.: Using tracer observations to reduce the uncertainty of ocean diapycnal mixing and climate-carbon cycle projections, Global Biogeochem. Cy., 23, gB4009, https://doi.org/10.1029/2008GB003421, 2009.

Smith, P., Davis, S. J., Creutzig, F., Fuss, S., Minx, J., Gabrielle, B., Kato, E., Jackson, R. B., Cowie, A., Kriegler, E., van Vuuren, D. P., Rogelj, J., Ciais, P., Milne, J., Canadell, J. G., McCollum, D., Peters, G., Andrew, R., Krey, V., Shrestha, G., Friedlingstein, P., Gasser, T., Grübler, A., Heidug, W. K., Jonas, M., Jones, C. D., Kraxner, F., Littleton, E., Lowe, J., Moreira, J. R. J. R., Nakicenovic, N., Obersteiner, M., Patwardhan, A., Rogner, M., Rubin, E., Sharifi, A., Torvanger, A. A., Yamagata, Y., Edmonds, J., Yongsung, C., Grubler, A., Heidug, W. K., Jonas, M., Jones, C. D., Kraxner, F., Littleton, E., Lowe, J., Moreira, J. R. J. R., Nakicenovic, N., Obersteiner, M., Patwardhan, A., Rogner, M., Rubin, E., Sharifi, A., Torvanger, A. A., Yamagata, Y., Edmonds, J., and Yongsung, C.: Biophysical and economic limits to negative $\mathrm{CO}_{2}$ emissions, Nat. Clim. Change, 6, 42-50, https://doi.org/10.1038/nclimate2870, 2016.

Stocker, T. and Schmittner, A.: Influence of $\mathrm{CO}_{2}$ emission rates on the stability of the thermohaline circulation, Nature, 388, 862865, 1997. 
Tavoni, M. and Socolow, R.: Modeling meets science and technology: an introduction to a special issue on negative emissions, Climatic Change, 118, 1-14, https://doi.org/10.1007/s10584-0130757-9, 2013.

Tokarska, K. B. and Zickfeld, K.: The effectiveness of net negative carbon dioxide emissions in reversing anthropogenic climate change, Environ. Res. Lett., 10, 094013, https://doi.org/10.1088/1748-9326/10/9/094013, 2015.

Trossman, D. S., Palter, J. B., Merlis, T. M., Huang, Y., and Xia, Y.: Large-scale ocean circulation-cloud interactions reduce the pace of transient climate change, Geophys. Res. Lett., 43, 3935-3943, https://doi.org/10.1002/2016GL067931, 2016.

UVic ESCM Developers Group: UVic ESCM 2.9, available at: http: //climate.uvic.ca/model/2.9/, last access: 19 February 2018.

Weaver, A. J., Eby, M., Wiebe, E. C., Bitz, C. M., Duffy, P. B., Ewen, T. L., Fanning, A. F., Holland, M. M., MacFadyen, A., Matthews, H. D., Meissner, K. J., Saenko, O., Schmittner, A., Wang, H., and Yoshimori, M.: The UVic earth system climate model: Model description, climatology, and applications to past, present and future climates, Atmos. Ocean, 39, 361-428, https://doi.org/10.1080/07055900.2001.9649686, 2001.

Wu, P., Wood, R., Ridley, J., and Lowe, J.: Temporary acceleration of the hydrological cycle in response to a $\mathrm{CO}_{2}$ rampdown, Geophys. Res. Lett., 37, L12705, https://doi.org/10.1029/2010GL043730, 2010.
Wu, P., Jackson, L., Pardaens, A., and Schaller, N.: Extended warming of the northern high latitudes due to an overshoot of the Atlantic meridional overturning circulation, Geophys. Res. Lett., 38, 1-5, https://doi.org/10.1029/2011GL049998, 2011.

Zickfeld, K., Eby, M., Alexander, K., Weaver, A. J., Crespin, E., Fichefet, T., Goosse, H., Philippon-Berthier, G., Edwards, N. R., Holden, P. B., Eliseev, A. V., Mokhov, I. I., Feulner, G., Kienert, H., Perrette, M., Schneider von Deimling, T., Forest, C. E., Friedlingstein, P., Joos, F., Spahni, R., Steinacher, M., Kawamiya, M., Tachiiri, K., Kicklighter, D., Monier, E., Schlosser, A., Sokolov, A., Matsumoto, K., Tokos, K. S., Olsen, S. M., Pedersen, J. O. P., Ridgwell, A., Shaffer, G., Yoshimori, M., Zeng, N., and Zhao, F.: Long-term climate change commitment and reversibility: an EMIC intercomparison, J. Climate, 26, 5782-5809, https://doi.org/10.1175/JCLI-D-1200584.1, 2013.

Zickfeld, K., MacDougall, A. H., and Matthews, H. D.: On the proportionality between global temperature change and cumulative $\mathrm{CO}_{2}$ emissions during periods of net negative $\mathrm{CO}_{2}$ emissions, Environ. Res. Lett., 11, 055006, 2016.

Zickfeld, K., Solomon, S., and Gilford, D. M.: Centuries of thermal sea-level rise due to anthropogenic emissions of shortlived greenhouse gases, P. Natl. Acad. Sci. USA, 114, 657-662, https://doi.org/10.1073/pnas.1612066114, 2017. 